\title{
Sobre os dias atuais: neoconservadorismo, escolas cívico- militares e o simulacro da gestão democrática
}

\author{
On the current days: neoconservadorism, civic-military schools and the \\ simulacrum of democratic management \\ Sobre días actuales: neoconservadurismo, escuelas cívico-militares y el \\ simulacro de la gestión democrática \\ ANDRÉ ANTUNES MARTINS
}

\begin{abstract}
Resumo: Este artigo tem como objetivo analisar, inicialmente, a aliança entre o neoconservadorismo e o neoliberalismo no campo educacional, assim como, os desdobramentos desse processo no avanço das parcerias das redes públicas educacionais com as instâncias militares. Fizemos uma revisão dos documentos que normatizam essas alianças, sobretudo, do Estado de Goiás e do Distrito Federal. Consideramos que ideia de gestão democrática é apresentada nos documentos, mas sem intenção de efetividade, visto os diferentes dispositivos de (re) disciplinarização e produtividade que abrandam a vida comum.
\end{abstract}

Palavras-chave: educação, gestão democrática, militarismo, conservadorismo.

Abstract: This article aims at analyzing, initially, the alliance between neoconservatism and neoliberalism in the educational field, as well as the unfolding of this process in the advance of public education networks partnerships with the military. We did a review of the documents that normalize these alliances, mainly, of the State of Goiás and the Federal District. We consider that the idea of democratic management is presented in the documents, but without the intention of effectiveness, considering the different devices of (re) disciplinarization and productivity that soften the common life.

Keywords: education, democratic management, militarism, conservatism.

Resumen: Este artículo tiene como objetivo analizar, inicialmente, la alianza entre el neoconservadurismo y el neoliberalismo en el campo educativo, así como el desarrollo de este proceso en el avance de las asociaciones de redes de educación pública con los militares. Hicimos una revisión de los documentos que normalizan estas alianzas, principalmente, del Estado de Goiás y del Distrito Federal. Consideramos que la idea de gestión democrática se presenta en los documentos, pero sin intención de efectividad, considerando los diferentes dispositivos de (re) disciplinarización y productividad que suavizan la vida común.

Palabras clave: Educación, gestión democrática, militarismo, conservadurismo. 


\section{INTRODUÇÃO}

O movimento neoconservador ganhou consistência, amplitude e visibilidade no campo educacional pelas ações conhecidas como 'escola sem partido' que, de certa forma, se disseminou no país por iniciativas legislativas, em diversos entes federados, para efetivar limites a uma suposta doutrinação dos docentes. Por sua vez, as escolas cívico-militares, também expressão contemporânea desse movimento neoconservador, vêm-se expandindo em diversas regiões do país. Essa proposta foi pauta de programa de governo na campanha eleitoral presidencial em 2018 e, neste momento, por iniciativa do executivo nacional, como também de estados e municípios, há algum tempo, alguns desdobramentos de institucionalização começam a se efetivar.

Nossa intenção neste texto é, inicialmente, estudar as peculiaridades, no campo educacional, da articulação do movimento neoconservador com a vertente neoliberal. Esta, com seus desdobramentos em curso desde os anos 1990, vem criando condições para a institucionalização do campo conservador na educação. Num segundo momento, imbricado ao anterior, visa-se a analisar as iniciativas institucionais do governo federal e, sobretudo, do estado de Goiás e do Distrito Federal, que já concretizaram parcerias com instâncias militares, avaliando os documentos que definem a gestão democrática no âmbito específico dessas colaborações.

\section{ARTICULAÇÕES NEOCONSERVADORAS E NEOLIBERAIS}

Acreditamos que, contemporaneamente, a perspectiva neoconservadora agudiza uma ruptura com as experiências instituintes em defesa da escola pública no período de redemocratização. Destacamos que esse movimento de ruptura não é novo, mas ganha novos contornos na atualidade.

As vivências democratizantes marcaram o período de transição na Nova República e, de maneira mais ou menos intensa, reconfiguraram o campo educacional pelo desejo de participação na gestão administrativa, financeira e didático-pedagógica. Devedoras desse período, de certa forma, a Constituição de 1988 e a Lei 9.394 de 1996, a LDB, delineiam a importância de instâncias democráticas no campo educacional. OLIVEIRA (2010) argumenta que a legislação educacional nesse período foi tensionada para contemplar o trabalho coletivo, como: a incumbência dos estabelecimentos de ensino na elaboração da proposta pedagógica e a efetiva participação das famílias e da comunidade no processo deliberativo colegiado.A própria noção de qualidade escolar passa por esse envolvimento participativo comunitário, ou seja, a referência social torna-se 
princípio organizador das redes e das escolas públicas (PARO, 2000) Portanto, não seria razoável pensar a gestão pública por orientações discrepantes da noção do comum.

O comum, como perspectiva democrática, visa a abolir as estruturas e instituições dominantes; é o campo das singularidades/multiplicidades, da liberdade revolucionária e em nada se assemelha a lógica da propriedade. Essa experiência comunitária é dispositivo para criação de novas subjetividades, de processos de inovação social e institucional (NEGRI; HARDT, 2016). Os autores argumentam que a abolição das instituições que corrompem o comum e incrementam a subordinação dos minoritários deve dar-se como tarefa democrática de construção revolucionária de outras formas institucionais. Os processos recentes em defesa da elaboração e vivência da gestão pública educacional são devedores dessa compreensão ao ter como objetivo uma orientação ampla e efetiva de participação democrática.

A despeito dessa intensa mobilização por processos de constituição do comum no campo educacional, de forma concomitante, no contexto da redemocratização, a matriz neoliberal começa a ser introduzida nas políticas educacionais, configurando, desde os anos 1990, um embate entre concepções e práticas. Ou seja, de um lado, a orientação neoliberal pautada em privatizações, desregulamentações e em políticas de resultados, próprias da lógica de mercado (CAMINI, 2013). De outro, em pleno conflito, a perspectiva de gestão democrática com suas características de valorização das referências sociais, dos conselhos deliberativos e plurais, das elaborações de projetos pedagógicos na/pela efetiva participação comunitária etc.

Esse embate manifesto na virada dos anos 1980 e durante os anos 1990 vai-se caracterizando, cada vez mais, por uma tendência à institucionalização das políticas neoliberais e uma crescente ressemantização produtivista dos significados constituintes da gestão democrática, as quais são ancoradas, sobretudo, em políticas de avaliações externas e currículos nacionais.

A crise do capital financeiro, em 2008, poderia levar-nos a um deslocamento dessa predominância neoliberal, vistos, inclusive, os efeitos evidentes de uma política econômica desastrosa promotora de desigualdades e injustiças (SAFATLE, 2017). A despeito desse fato, a segunda onda neoliberal acontece, mas, nesse momento, apoiada no discurso do medo, da promoção contínua de uma guerra civil e do racismo. A gestão da segurança pública encaminha a militarização da vida e a definição de territórios onde a ordem deve ser estabelecida, inclusive, com mecanismos de exceção (TELES, 2018). É justamente nesse cenário, de estado de sítio permanente, no qual a vida cotidiana é militarizada e o exercício do direito de matar deixa de ser uma exclusividade do 
Estado (MBEMBE, 2018), que o movimento conservador encontra terreno fértil para aliar-se aos liberais, numa aliança que se materializa pela administração da insatisfação, do desencanto e da falta (SAFATLE, 2017). Esse estado policial que faz morrer, portanto, é uma resposta à necessidade de conservação das condições necessárias à produção capitalista no momento de crise.

Compreendemos que essa aliança contemporânea entre liberais e conservadores, quando analisada no campo educacional, encontra dispositivos institucionais, na Reforma de Estado de 1990, que favoreceram seu surgimento. Um deles foi o incentivo a gestão pública gerencial que propugnava, entre outros, uma flexibilização das instâncias educacionais e escolares por meio de parcerias com o terceiro setor e empresas (CAMINI, 2013). Diversos mecanismos são incrementados nesse momento; todos, de certa forma, ratificam a ideia central de esgotamento da gestão pública e a eficiência da gestão liberal gerencial. Algo que deu margem, portanto, ao cenário atual de terceirização da gestão das redes públicas, por meio da colaboração entre as instâncias militares e as secretarias de educação, compartilhando funções administrativas, financeiras e pedagógicas.

Outro argumento, para fazer valer esse arranjo colaborativo, é o da insegurança, o medo que atravessa o cotidiano das escolas, sobretudo das localizadas em áreas urbanas conflagradas. A colaboração com a instância militar visaria, entre outros motivos, a trazer tranquilidade aos pais e seus filhos nas escolas cerceadas pela violência urbana, como aos profissionais para que possam atuar com eficiência. Enquanto na matriz neoliberal há controle pós-fordista dos docentes, dos gestores, das escolas (e das famílias) pelo não alcance dos resultados, na matriz neoconservadora o controle fordista disciplinar se torna necessário para combater os desvios que provocam o caráter conturbado do cotidiano e do concomitante distanciamento dos valores tradicionais.

O estado policial, nesse momento, alcançaria o dia a dia das escolas instituindo condutas compatíveis com os valores da ordem. Embora compreendamos muitas das dificuldades dos profissionais da educação ao considerarmos a temática da violência, assim como a preocupação dos pais em relação a seus filhos, esse apelo pela militarização pode promover o efeito de silenciamento e consequente exclusão dos alunos, famílias e professores. Não duvidamos que escolas precarizadas dificilmente conseguirão promover iniciativas efetivas de enfrentamento dessa questão. Logo, não se trata de (re) disciplinar a escola como solução, mas de garantir condições adequadas de funcionamento dos equipamentos públicos, atendimento dos profissionais da educação em suas peculiaridades de trabalho, aproximação da comunidade pelo fortalecimento dos espaços públicos deliberativos etc. 
Essas parcerias avançam em estados e municípios e em diferentes regiões do país, sinalizando aprofundamentos autoritários em plena contramão aos desejos recentes de realização de uma escola democrática. Nessa perspectiva, cabe indagar sobre os efeitos dessa aliança do produtivismo e da ordem nas possibilidades de realização da gestão democrática na atualidade.

\section{ESCOLAS CÍVICO-MILITARES}

Como era aguardado, a julgar pela proposta na campanha eleitoral presidencial de 2018, a ideia de militarização da rede escolar básica começa a ganhar feição institucional nacional pelo Decreto $n^{\circ}$ 9465, de 2 de janeiro de 2019 (BRASIL, 2019), que aprova a nova estrutura regimental do Ministério da Educação. De maneira mais clara, há, junto à Secretaria de Educação Básica, a criação de uma Subsecretaria de Fomento às Escolas Cívico-Militares, tendo como competência direta

Promover, fomentar, acompanhar e avaliar, por meio de parcerias, a adoção por adesão do modelo de escolas cívico-militares nos sistemas de ensino municipais, estaduais e distrital tendo como base a gestão administrativa, educacional e didático-pedagógica adotada por colégios militares do Exército, Polícias e Bombeiros Militares; (BRASIL, 2019, Art. 11, XVI, grifo nosso).

E ainda, complementando:

II propor e desenvolver um modelo de escola de alto nível, com base nos padrões de ensino e modelos pedagógicos empregados nos colégios militares do Exército, das Polícias Militares e dos Corpos de Bombeiros Militares, para os ensinos fundamental e médio; [...] III promover, progressivamente, a adesão ao modelo de escola de alto nível às escolas estaduais e municipais, mediante adesão voluntária dos entes federados, atendendo, preferencialmente, escolas em situação de vulnerabilidade social; (Idem, Art. 16, XVI, grifo nosso).

A nova pasta teria como função precípua articular a parceria, por adesão, dos entes federados,ao modelo de gestão realizado nas escolas militares. Notase que a gestão à qual se refere o documento abarca o âmbito administrativo e didático-pedagógico, e a qualificação do modelo em questão, é referida como sendo de alto nível. Parceria por adesão soa sempre como um eufemismo quando estados e municípios, estando de acordo ou não com a proposta, são praticamente obrigados à adesão, em virtude dos benefícios materiais e/ou financeiros disponibilizados, pois, em sua maioria, apresentam grandes dificuldades em manter as redes. Portanto, nem sempre as colaborações acontecem por ampla concordância, mas por circunstâncias estruturais. 
A menção ampla ao caráter da gestão, abarcando o administrativo e o didático pedagógico e seu correspondente alto nível não é dissimulado no documento. De fato, como veremos nos exemplos adiante, essa separação não deveria ser concebível, sobretudo, quando a linha de força disciplinar e hierarquizante é majoritária. Ou seja, o campo da ordem conservadora não se contenta com uma administração burocrática segmentada, restrita ao campo documental, mas, certamente, almeja espraiar-se pelo comum ou pelos mais públicos e plurais espaços deliberativo-pedagógicos para colocá-los em acordo ao modelo da caserna.

Ao tomarmos como exemplo a escola de formação dos cadetes das forças armadas, os valores de obediência, submissão, dependência, paternalismo, assiduidade, pontualidade, racionalidade e meritocracia concebem um determinado modo de vida social e político peculiar à proposta formativa militar (LUDWIG, 1998), portanto, a menção a gestão, mesmo que se pretenda preservar a autonomia pedagógica dos entes federados, deve ser entendida de forma ampla a abarcar os diferentes domínios da vida educacional e escolar, colocando-os sob a perspectiva formativa militar.

Outro aspecto que corrobora essa assertiva de impossibilidade de uma gestão segmentada e/ou restrita está na qualificação 'alto nível', pois denota o entendimento de um rendimento desejável a ser alcançado. Logo, a afirmação de uma de orientação pedagógica vinculada ao produtivismo, que esmaece qualquer compreensão em relação a uma eventual permanência da autonomia pedagógica curricular das escolas. Vale destacar que a aliança à qual nos referimos anteriormente tem uma explicitação neste momento, quando o campo conservador é necessário para garantir o alto nível da gestão e da aprendizagem, pelas perspectivas meritocráticas.

Algumas experiências, já existentes nos estados, são potenciais balizadores para a política nacional. O estado de Goiás, por exemplo, foi, provavelmente, pioneiro na introdução de um modelo em que a gestão foi entregue à polícia militar, mais especificamente, pela implantação do Colégio Militar da Polícia de Goiás (CPMG).

Em 2001 foi criado o CPMG (Colégio da Polícia Militar de Goiás), o antigo Colégio Estadual Hugo de Carvalho Ramos, com a Lei Estadual n¹4.050, através da Lei de iniciativa do Executivo, aprovada pela Assembleia Legislativa em caráter de urgência, transformou escolas estaduais em instituições de ensino geridas pela Polícia Militar do Estado de Goiás (PMGO) (GUIMARÃES, 2017, p.10). 
A autora argumenta que a partir desse momento houve a intensificação de transferências das escolas estaduais para a gestão da Polícia Militar, e afirma que, até 2016, quarenta e sete escolas já constavam como CMPG (Idem, Ibidem).

$O$ primeiro aspecto a ser destacado diz respeito à forma de pactuação existente entre as Secretarias de Segurança Pública e de Educação. Os CMPG estão vinculados à estrutura hierárquica da primeira secretaria por meio do Comando de Ensino Policial Militar (CEPM) e a segunda torna-se uma parceira no processo de gestão dessas escolas específicas:

\begin{abstract}
Art. $1^{\circ}$ O Colégio da Polícia Militar do Estado de Goiás, (...) está subordinado à Secretaria da Segurança Pública por meio da Polícia Militar do Estado de Goiás, através do Comando de Ensino Policial Militar, Unidade Gestora de Grande Comando onde se encontram inseridos os Colégios da Polícia Militar do Estado de Goiás, tendo como parceira a Secretaria Estadual de Educação - SEE, por meio do Termo de Cooperação Técnico pedagógico (GOIÁS, 2015, art $1^{\circ}$, grifo nosso).
\end{abstract}

A subordinação da Secretaria de Educação, ao Comando de Ensino da Polícia Militar, enseja uma articulação cujo protagonismo estará num setor com uma expertise incomum aos processos de gestão educacionais de uma rede pública. O campo da segurança pública, embora seja um tema transversal importante em educação, não se confunde e, muito menos, substitui a organização e gestão de escolas públicas cujos princípios estão pautados pela participação deliberativa plural.

O Regimento Interno do CPMG, como artifício, tende a contemplar a legislação atual que confere legalidade à gestão democrática na rede pública; contudo, contraditoriamente, sinaliza um centro deliberativo forte e o consequente esvaziamento das redes e das escolas como lugar de decisão.

\footnotetext{
A gestão escolar democrática e colegiada é entendida como o processo que rege o funcionamento do CPMG, compreendendo tomada de decisão conjunta no planejamento, execução, acompanhamento e avaliação das questões pedagógicas e administrativas com a participação do Comando de Ensino Policial Militar - CEPM, como unidade gestora dos CPMG e de toda a comunidade escolar (GOIÁS, 2015, art 5º, grifo nosso).
}

Neste artigo, a sinalização da centralidade do Comando de Ensino Policial Militar (CEPM) explicita-se numa espécie de organização dual, onde essa instância, tomada como unidade gestora, de fato exerce essa função pelo princípio do comando, algo próprio ao contexto militar. A comunidade escolar é entendida na/pela negação do status de grupo gestor, como um grupo à parte, com prerrogativas deliberativas limitadas. Há, nesse arranjo organizativo, a nucleação 
de um centro de poder separado da comunidade. Esse entendimento fica mais evidente pela existência de um Conselho Geral dos CPMG organizado com base numa forte hierarquia de comando, cuja presidência e vice-presidência cabem, respectivamente, ao comandante e subcomandante do CEPM (Idem, art. $8^{\circ}$ ).

O Conselho Escolar, por sua vez, margeia o campo figurativo da gestão, torna-se um conselho auxiliar, tendo que se enquadrar às padronizações definidas no Conselho Geral.

O Conselho Geral Colegiado dos CPMG é o órgão representativo das partes envolvidas no processo de ensino dos CPMG e comunidade escolar (...) suas decisões e deliberações possuem caráter de padronização de procedimentos administrativos e financeiros no âmbito dos CPMG, as quais serão adotadas imediatamente por todos os entes participantes de sua composição (Idem, art $9^{\circ}$, grifo nosso).

A padronização para um imediato cumprimento das decisões fica evidente nesse cenário organizativo. O Conselho Geral, como instância central e hierarquicamente acima das que atuam nas escolas, limita fortemente o campo deliberativo destas. Corrobora essa perspectiva a definição de uma fiscalização em questões administrativas, financeiras e pedagógicas (Idem, art. 10, \2 2, $\mathrm{VIII})$; logo, enfaticamente, desconfigura nos espaços ordinários escolares as possibilidades efetivas de se estabelecerem laços democráticos em suas localidades. A cadeia deliberativa se verticaliza, enrijece-se e cria dispositivos de controle para a sua reprodução.

Como se não bastasse, a composição do Conselho Escolar também é modificada pela redução de quem pode ocupar os cargos diretivos nas escolas, sendo de direito regimental, reservados aos oficiais: nas funções de diretor comandante e subcomandante, na divisão disciplinar do corpo discente, na divisão de ensino e na coordenação pedagógica (GOIÁS, 2015, arts. 14, 17, 19, 21 e 22). Todas essas funções, no topo de uma hierarquia organizacional, são ocupadas exclusivamente por militares. Não cabe, nesse modelo, qualquer tipo de consulta à comunidade para designar gestores. Embora docentes, pais e alunos possam participar do Conselho Escolar, evidentemente, o arranjo participativo/ deliberativo se torna um arremedo democrático.

O projeto piloto de Gestão Compartilhada do Distrito Federal (DISTRITO FEDERAL, 2019), por sua vez, inova aparentemente em relação à proposta anterior, apresentando uma configuração organizativa de colaboração, por divisão de funções, entre a Secretaria de Educação e a de Segurança Pública. Esta, por meio da Polícia Militar, ficará responsável pela gestão disciplinar cidadã 
e àquela caberá a gestão pedagógica e, ainda, a gestão estratégica administrativa será compartilhada entre as pastas; conquanto, a equipe executiva desta última será disposta pela Secretaria de Segurança.

Embora os objetivos anunciados sejam de resguardar a centralidade da escola no sistema e seu caráter público quanto à gestão (DISTRITO FEDERAL, 2012, art $2^{\circ}$ ), esse imbróglio organizativo cria, de fato, uma estrutura tripartite em pleno desacordo com a compreensão de uma gestão democrática. O que se verifica é a impropriedade de se separar o administrativo do pedagógico por secretarias, como se eles não se atravessassem e se influenciassem mutuamente. Em outros termos, essa tentativa de modelo híbrido, com suas características patriótico-cívicas, conjuga a introdução de uma linha de força deliberativa pela especialização/separação de funções, simulando uma suposta autonomia das pastas nas atividades designadas. Não duvidamos de que esse artificialismo favoreça o simulacro de uma gestão democrática.

\section{CONSIDERAÇÕES FINAIS}

Não negligenciamos a ideia de que os efeitos da aliança do produtivismo e da ordem são nefastos, pois, para se afirmarem, valem-se da produção e da consequente e necessária manutenção de narrativas de esgotamento da gestão pública. Nesse sentido, o simulacro da gestão democrática foi a forma encontrada para dar uma aparência de legalidade às parcerias com as instâncias militares. Isso se deve ao fato de a gestão democrática ser um preceito constitucional; sendo assim, ainda que formalmente, ela deve figurar nos princípios anunciados dos documentos que regulamentam essas parcerias, mesmo que, de fato, não haja intenção de se vivenciá-la. Afinal, a congruência do discurso da falência da gestão pública está, exatamente, na proposição de outras formas de gestão, ou seja, no exato oposto da gestão democrática.

Nesse sentido, a perspectiva de parceria entre o setor militar e as secretarias de educação é um eufemismo para o exercício do controle por meio da (re)introdução de dispositivos disciplinares. A gestão da ordem visa a espraiarse pelos diferentes campos de atuação das escolas, por meio de dinâmicas hierarquizantes e ortopédicas, desautorizando, assim, qualquer possibilidade de autonomia pedagógica dos docentes e/ou da comunidade escolar.

Nesse contexto, almeja-se a democratização de um ensino de alta qualidade semelhante ao modelo das escolas das corporações militares. Essa qualificação pode ser traduzida pelo rendimento em exames; portanto, uma vinculação reducionista da aprendizagem a resultados. Não podemos desconsiderar os efeitos 
excludentes de uma formação que deslegitima as referências sociais e culturais de grupos populares ao limitar-se ao rendimento, sobretudo, sabendo que essas parcerias estão sendo realizadas, em boa parte, em escolas periféricas.

Enfim, poderíamos argumentar que existe um duplo dispositivo excludente de controle: pela permanência do rendimento meritocrático, numa aproximação aos pressupostos produtivistas liberais; como pelo silenciamento imposto pela ordem disciplinar policialesca, no afã de combate à violência. $\mathrm{Na}$ base desses dispositivos, o simulacro da gestão democrática que desvirtua a constituição do comum ou qualquer iniciativa de valorização e legitimação das formas de vidas minoritárias.

\section{REFERÊNCIAS}

BRASIL. Decreto No 9.465, DE 2 de janeiro de 2019. Aprova a Estrutura Regimental e o Quadro Demonstrativo dos Cargos em Comissão e das Funções de Confiança do Ministério da Educação. Disponível em: $\quad<$ https://brasil.estadao.com.br/blogs/vencerlimites/wpcontent/ uploads/sites/189/2019/01/MINIST\%C3\%89RIOEDUCA \%C3\%87\%C 3\%83O_ESTRUTURA_DECRETO9465_02JANEIRO2019_DOU_IN_ blogVencerLimites.pdf>. Acesso em: jan. 2019.

CAMINI, Lucia. Política e gestão educacional brasileira: uma análise do Plano de Desenvolvimento da Educação/Plano de Metas Compromisso Todos pela Educação (2007-2009). São Paulo: Outras Expressões, 2013.

Distrito fEDERAL. Portaria Conjunta, nº1, de 31 de janeiro de 2019. Diário Oficial do Distrito Federal, $\mathrm{n}^{\circ}$ 23, sexta-feira, 1 de fevereiro de 2019. Disponível em: http://www.se.df.gov.br/wp-conteudo/uploads/2019/02/ portaria-conjunta-gestao-compartilhada_07fev19.pdf. Acesso em: fev. 2019.

DISTRITO FEDERAL. Lei Distrital $\mathbf{n}^{\mathbf{0}}$ 4751, de 07 de fevereiro de 2012. Disponível em: http://www.tc.df.gov.br/sinj/Norma/70523/ Lei_4751_07_02_2012.html. Acesso em: fev. 2019.

GOIÁS. Secretaria de Segurança Pública. Regimento Interno do Colégio da Polícia Militar do Estado de Goiás. Disponível em: <https://www. cpmganapolis.net/wp-content/uploads/2015/05/regimento interno.pdf>. Acesso em: jan. 2019. 
GUIMARÃES, Paula Cristina Pereira. Os novos modelos de gestão militarizadas das escolas estaduais de Goiás. XXIX Simpósio Nacional de História. Brasília, Julho de 2017. Disponível em: https://www.snh2017.anpuh.org/resources/ anais/54/1502846486_ARQUIVO_TRABALHO_COMPLETO_ANPUH_Paula_2017(1).pdf. Acesso em: jan. 2019.

LUDWIG, Antonio Carlos Wil. Democracia e ensino militar. São Paulo: Cortez Editora, 1998.

MBEMBE, Achille. Necropolítica. Biopoder, soberania, estado de exceção, política da morte. $3^{a}$ edição. São Paulo: n-1 edições, 2018.

NEGRI, Antonio; HARDT, Michael. Bem estar comum. Rio de Janeiro: Record, 2016.

OLIVEIRA, Dalila Andrade. Mudanças na organização e na gestão do trabalho na escola. In: OLIVEIRA, Dalila Andrade; ROSAR, Maria de Fátima Felix. Política e gestão da educação. $3^{\text {a }}$ Edição, Belo Horizonte: Autêntica, 2010.

PARO, Vitor Henrique. Gestão democrática da escola pública. $3^{a}$ Edição. São Paulo: Ática, 2000.

SAFATLE, Vladimir. Só mais um esforço. São Paulo: Três Estrelas, 2017.

TELES, Edson. A produção do inimigo e a insistência do Brasil violento e de exceção. In: GALLEGO, Esther Solano (org.). O ódio como política. A reinvenção das direitas no Brasil. São Paulo: Boitempo, 2018.

ANDRÉ ANTUNES MARTINS é Doutor em Educação pela Universidade Federal Fluminense/RJ. Atualmente é professor adjunto na mesma universidade do doutoramento. Desenvolve pesquisa no campo das ações coletivas de produção do comum e das políticas com foco na gestão democrática educacional. Também atuou em redes públicas de ensino na educação básica.

E-mail: andreantmartins@gmail.com

Recebido em julho de 2019 Aprovado em setembro de 2019 